\title{
MANAJEMEN RISIKO KECELAKAAN KERJA BERDASARKAN OHSAS 18001:2007 DI SUBDEP PERKAKAS PT PINDAD (PERSERO) - DIVISI MUNISI
}

\author{
Lindawati Hermawan*(koresponden), Sahala Manalu, dan Daniel Prasetyo* \\ lindawati.hermawan@gmail.com, sahala.manalu@machung.ac.id, \\ Universitas Ma Chung Malang \\ Abstrak
}

Every manufacturing company faces safety risks in its production process. OHSAS 18001:2007 certification is required by international companies for ensuring that they have good safety and health management. The purpose of this research is to identify, assess, and define mitigation for safety risk in PT Pindad (Persero) - Munition Division's Appliance Sub-Department based on OHSAS 18001:2007. The result shows that the safety risk factors in Appliance SubDepartments are electricity shock, tools graze, tools cut, sprained limb, tools crush, dust and grindstone fragments, and cutting oil burst. Those risks happen because of human behavior, infrastructure, and working tool factors as shown in fishbone diagram. Most safety risks are included in low risk category and can be handled through administrative controls and personal protective equipment (PPE) usage. Some safety risks are included in medium risk category and need to be handled through engineering control and PPE usage.

Keywords: OHSAS 18001:2007, Risk Identification, Risk Assessment, Mitigation

$$
\text { Pendahuluan }
$$
manufaktur, perusahaan akan selalu berhadapan dengan risiko kecelakaan kerja dalam proses produksinya. Seiring dengan perkembangan zaman, ada banyak perusahaan yang mulai beroperasi secara internasional. Negara-negara maju yang peduli dengan hak asasi manusia menuntut semua perusahaan internasional untuk memiliki sertifikasi manajemen keselamatan sebagai salah satu persyaratan bisnis dan tanda bahwa $\begin{array}{lr}\text { perusahaan } & \text { tersebut telah } \\ \text { menerapkan } & \text { manajemen }\end{array}$ keselamatan kerja yang baik.

Sertifikasi mengenai keselamatan kerja diciptakan pada tahun 1999 dan disebut dengan OHSAS 18001:1999. Pada tahun 2007, standar ini mengalami revisi dan disebut dengan OHSAS 18001:2007. Sertifikasi adalah proses dimana pihak tertentu memberikan jaminan tertulis bahwa sebuah produk, jasa, sistem, proses, atau bahan baku sesuai dengan persyaratan tertentu (Dunmire 
2002). Meskipun sertifikasi bisa didapatkan melalui penilaian sendiri maupun audit dari pelanggan, sertifikasi dari pihak ketiga lebih dapat dipercaya karena pihak tersebut tidak terikat dengan pihak yang disertifikasi; sehingga tidak akan muncul konflik kepentingan antara pihak yang disertifikasi dan pihak penilai.

PT Pindad (Persero) -

Divisi Munisi menghadapi risiko kecelakaan kerja yang besar karena berhadapan dengan bubuk mesiu yang mudah terbakar. Beberapa tahun yang lalu, ada seorang karyawan yang lalai dalam menjalankan prosedur pemindahan kotak yang berisi munisi. Setiap kotak seharusnya dipindahkan dengan menggunakan kereta dorong, namun ia memindahkannya dengan cara menyeret kotak tersebut. Pada akhirnya, terjadi percikan api dan terjadi ledakan yang menewaskannya. Kejadian ini memberikan catatan buruk bagi PT Pindad (Persero) dalam usahanya untuk mencapai prestasi zero accident.

Perusahaan ini telah memasarkan produknya keluar negeri; sehingga perlu memiliki sertifikasi OHSAS 18001:2007 agar tidak mengalami kendala dalam pemasarannya. Seperti yang telah disebutkan di atas, sertifikasi semacam ini dibutuhkan sebagai tanda bahwa PT Pindad (Persero) memenuhi hak asasi karyawannya dengan menjamin keselamatan kerja mereka; sehingga negara-negara yang peduli dengan hak asasi manusia akan membuka pasar mereka bagi PT Pindad (Persero). PT Pindad (Persero) telah memiliki sertifikat OHSAS 18001:2007 dari Lloyds Register Quality Assurance (LRQA) pada tahun 2011. Namun dalam proses penilaian risikonya, perusahaan ini baru memiliki list register (daftar risiko) untuk bahaya mekanik/risiko fisik yang terkait dengan aktivitas rutin perusahaan. Dalam OHSAS 18001:2007 tertulis bahwa hal yang perlu diperhatikan dalam proses penilaian risiko adalah aktivitas rutin dan tidak rutin, perilaku manusia, kemampuan karyawan, serta faktor lainnya.

Penelitian ini berfokus pada penilaian risiko kecelakaan kerja di Sub-departemen (Subdep) Perkakas karena data yang terkait 
subdep lain bersifat rahasia. Ada tiga tujuan dari penelitian ini yaitu (1) menganalisis risiko kecelakaan kerja yang ada di Subdep Perkakas, (2) mengukur tingkat kejadian dan dampak risiko kecelakaan kerja yang ada, dan (3) merumuskan strategi mitigasi risiko kecelakaan kerja.

$$
\text { Dalam operasionalnya, }
$$

Subdep Perkakas bertanggung jawab untuk menyediakan sparepart maupun tools yang dibutuhkan oleh subdep lain dalam proses produksi dan membutuhkan alat kerja seperti mesin gergaji, mesin bubut, dan sebagainya. Para karyawan Subdep Perkakas menghadapi risiko kecelakaan kerja seperti terpotong mesin gergaji, terjepit mesin bubut, dan lain-lain. Kecelakaan kerja semacam ini dapat mengakibatkan terputusnya jari maupun sebagian anggota tubuh karyawan dan mengakibatkan cacat tetap.

Variabel risiko yang akan dibahas dalam penelitian ini adalah variabel risiko aktivitas rutin, variabel risiko perilaku manusia, serta variabel infrastruktur dan peralatan kerja yang disediakan. Dengan adanya identifikasi risiko kecelakaan yang lebih lengkap, PT
Pindad (Persero) dapat menetapkan berbagai langkah pencegahan dan penanganan risiko agar kecelakaan kerja dapat diminimalisir. Setelah mengetahui risiko yang ada, penulis mencari tahu tingkat kejadian dan dampak risiko, serta merumuskan langkah yang dapat diambil oleh perusahaan.

\section{Tinjauan Pustaka}

Proses penilaian risiko terdiri dari proses identifikasi risiko, penilaian tingkat kejadian, dan dampak risiko (OHSAS, 2007). Halhal yang perlu diperhatikan dalam proses identifikasi risiko menurut OHSAS 18001:2007 adalah:

a. Aktivitas rutin dan tidak rutin yang dilakukan

b. Aktivitas semua orang yang memiliki akses ke tempat kerja termasuk pengunjung dan kontraktor dari luar perusahaan

c. Perilaku manusia, kemampuan karyawan, serta faktor lain yang berkaitan dengan manusia

d. Risiko dari luar tempat kerja yang dapat berpengaruh pada perusahaan

e. Infrastruktur, peralatan, dan material di tempat kerja 
f. Perubahan maupun perubahan yang sedang direncanakan di perusahaan

g. Modifikasi SMK3 termasuk perubahan sementara

h. Desain tempat kerja, proses, peralatan yang digunakan, serta prosedur standar operasional yang berlaku di perusahaan

Dalam Panduan SMK3

PT Pindad (Persero) yang diputuskan melalui kebijakan direksinya, tingkat kejadian risiko digolongkan menjadi lima yaitu:

a. Jarang terjadi: frekuensinya paling banyak satu kali dalam setahun

b. Kondisi abnormal: frekuensi terjadinya sekitar $2-10$ kali dalam setahun

c. Sering: frekuensi terjadinya sekitar 11 - 20 kali dalam setahun

d. Sering sekali: frekuensi terjadinya sekitar 21 - 40 kali dalam setahun

e. Terus menerus: frekuensi terjadinya lebih dari 40 kali dalam setahun

Untuk dampak kecelakaan dapat diklasifikasikan menjadi lima yaitu: a. Near-miss: kondisi berbahaya yang bisa mengakibatkan kecelakaan namun belum berakibat luka atau rusaknya properti perusahaan.

b. First aid injury: kecelakaan kerja yang berakibat luka kecil dimana setelah korban diberi pertolongan pertama, ia dapat bekerja kembali.

c. Minor: kecelakaan yang berakibat luka, memerlukan perawatan rumah sakit, serta mengakibatkan hilangnya jam kerja lebih dari 24 jam namun tidak mengakibatkan cacat tetap.

d. Major: kecelakaan kerja yang berakibat luka, memerlukan perawatan rumah sakit, serta mengakibatkan hilangnya jam kerja lebih dari 24 jam dan mengakibatkan cacat tetap atau berkurangnya fungsi organ.

e. Fatal: kecelakaan yang berakibat fatal atau meninggal dunia.

Pada akhirnya dapat dibuat suatu matriks tingkat kejadian dan dampak risiko sebagai berikut: 
Tabel 1Matriks Tingkat Kejadian dan Dampak Risiko

\begin{tabular}{|c|c|c|c|c|c|}
\hline \multirow[b]{2}{*}{ Dampak risiko } & \multicolumn{5}{|c|}{ Tingkat kejadian risiko } \\
\hline & Jarang & $\begin{array}{l}\text { Kondisi } \\
\text { abnormal }\end{array}$ & Sering & $\begin{array}{l}\text { Sering } \\
\text { sekali }\end{array}$ & $\begin{array}{l}\text { Terus } \\
\text { Menerus }\end{array}$ \\
\hline Near-miss & $\mathrm{D}$ & $\mathrm{D}$ & $\mathrm{D}$ & $\mathrm{D}$ & $\mathrm{L}$ \\
\hline First aid injury & $\mathrm{L}$ & $\mathrm{L}$ & $\mathrm{L}$ & $\mathrm{L}$ & $\mathrm{M}$ \\
\hline Minor & $\mathrm{L}$ & $\mathrm{L}$ & M & M & $\mathrm{H}$ \\
\hline Major & M & M & $\mathrm{H}$ & $\mathrm{H}$ & $\mathrm{H}$ \\
\hline Fatal & $\mathrm{H}$ & $\mathrm{H}$ & $\mathrm{H}$ & $\mathrm{H}$ & $\mathrm{H}$ \\
\hline \multicolumn{6}{|c|}{ Sumber: PT Pindad (Persero) } \\
\hline \multicolumn{6}{|l|}{ Keterangan: } \\
\hline D: diabaikan & \multicolumn{5}{|c|}{ M: medium (sedang) } \\
\hline L: low (rendah) & \multicolumn{3}{|c|}{ H: high (tinggi) } & & \\
\hline
\end{tabular}

Risiko yang termasuk dalam kategori rendah akan ditangani dengan peringatan maupun kontrol administratif dan penggunaan alat pelindung diri; sedangkan risiko yang termasuk dalam kategori medium dan tinggi akan ditangani dengan cara eliminasi, substitusi, dan engineering control (PT Pindad 2007). Untuk risiko yang dapat diabaikan, risiko akan tetap dihadapi dengan pengendalian operasional melalui standard operational procedures (SOP). Hal ini ditetapkan sesuai dengan standar OHSAS 18001:2007. Berikut ini merupakan penjelasan lebih lanjut mengenai langkah penanganan risiko tersebut:

a. Eliminasi

Penanganan risiko akan dilakukan dengan menghilangkan kemunculan terjadinya risiko. Misalnya, menggunakan proses otomatisasi mesin dalam kegiatan sehariharinya sehingga kontak antara mesin dan karyawan dapat dikurangi.

b. Substitusi

Penanganan risiko dilakukan dengan mengganti sebagian atau seluruh peralatan, material, maupun hal lainnya yang dapat menimbulkan risiko. Misalnya, mengganti mesin yang sudah tua dengan mesin yang lebih baru dan memiliki teknologi yang lebih canggih.

c. Engineering control

Risiko akan dihadapi dengan kontrol rekayasa mesin. Misalnya, menyediakan alat pengaman yang terpasang pada 
mesin, pemasangan sensor, mengubah layout mesin, dan sebagainya.

d. Peringatan maupun kontrol administratif

Pencegahan risiko dapat dilakukan dengan memasang rambu-rambu peringatan bahaya bagi karyawan yang ada di tempat kerja serta membuat standar prosedur operasional (SOP) mengenai kegiatan yang ada. Nantinya, SOP ini akan dikomunikasikan pada seluruh karyawan yang terkait.

e. Alat pelindung diri (APD)

Risiko akan ditanggulangi dengan cara memberikan APD pada karyawan. Alat pelindung diberikan dengan tujuan untuk melindungi bagian tubuh tertentu yang menghadapi risiko kecelakaan ketika melakukan suatu aktivitas. Alat pelindung diri dapat berupa sarung tangan, kacamata, safety shoes, dan sebagainya.

Bird dan Germain dalam Panduan SMK3 PT Pindad (Persero) (2007) mengembangkan suatu model penyebab dan akibat kecelakaan kerja yang disebut dengan International Loss Control Institute atau ILCI pada tahun 1986. Model tersebut menjelaskan bahwa kerugian maupun kecelakaan kerja bermula dari lemahnya kontrol manajemen. Bila perusahaan memiliki kontrol manajemen yang baik, tingkat kecelakaan kerja dapat ditekan. Berikut ini merupakan alur penyebab dan akibat kerugian atau kecelakaan kerja berdasarkan model ini:

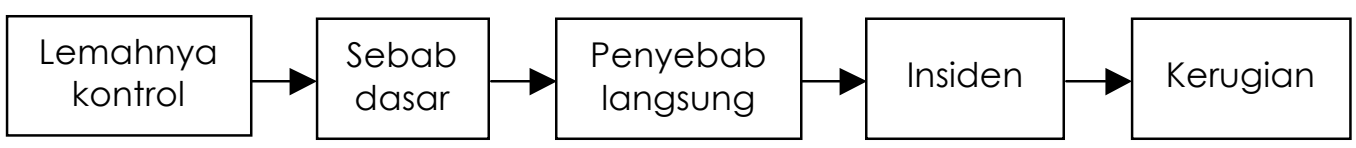

Gambar 1: Diagram alur penyebab dan akibat kerugian atau kecelakaan Sumber: PT Pindad (2007)

Lemahnya kontrol terjadi karena adanya program yang tidak sesuai, standar yang tidak sesuai, maupun pelaksanaan. Secara garis besar, pihak yang terkait dengan hal ini adalah manajemen perusahaan. Penyebab dasar kecelakaan dapat 
Tabel 2Penyebab Dasar Kecelakaan

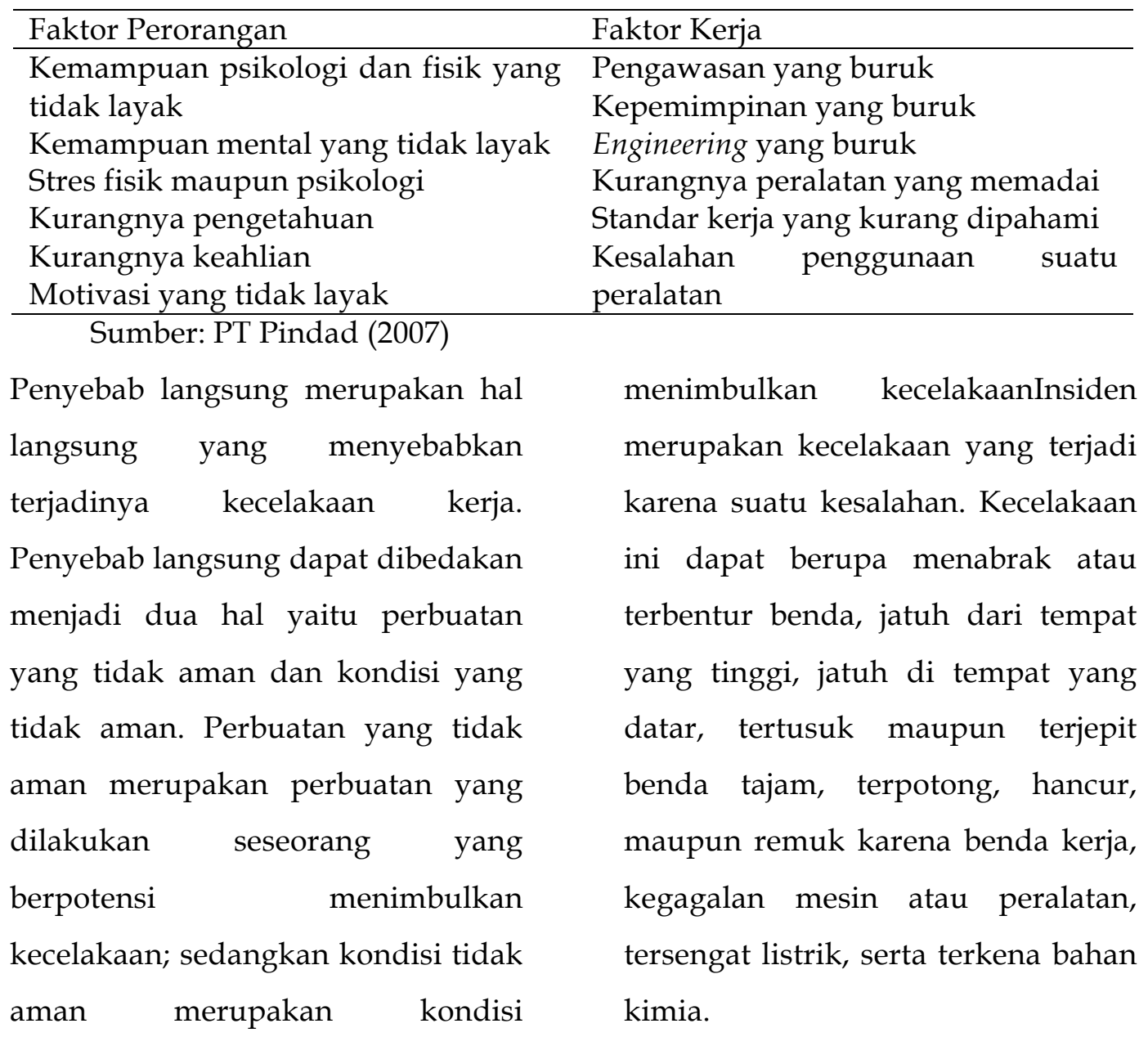

lingkungan kerja yang berpeluang

Tabel 3 Penyebab Langsung Kecelakaan

\begin{tabular}{|c|c|}
\hline Perbuatan Tidak Aman & Kondisi Tidak Aman \\
\hline Operasi tanpa otorisasi & Pelindung atau pembatas yang tidak \\
\hline Gagal memperingatkan perbuatan & layak \\
\hline tidak aman & Alat pelindung diri yang tidak layak \\
\hline Kecepatan tidak layak & Peralatan yang rusak \\
\hline Membuat alat pengaman & Ruang kerja yang sempit \\
\hline berfungsi & Sistem peringatan yang kurang \\
\hline Menggunakan alat yang rusak & Kebersihan dan kerapian tempat kerja \\
\hline $\begin{array}{l}\text { Menggunakan alat pelindung diri } \\
\text { yang tidak layak }\end{array}$ & $\begin{array}{l}\text { yang kurang } \\
\text { Kebisingan }\end{array}$ \\
\hline Pemuatan barang yang tidak layak & Terpapar radiasi dan suhu ekstrim \\
\hline
\end{tabular}




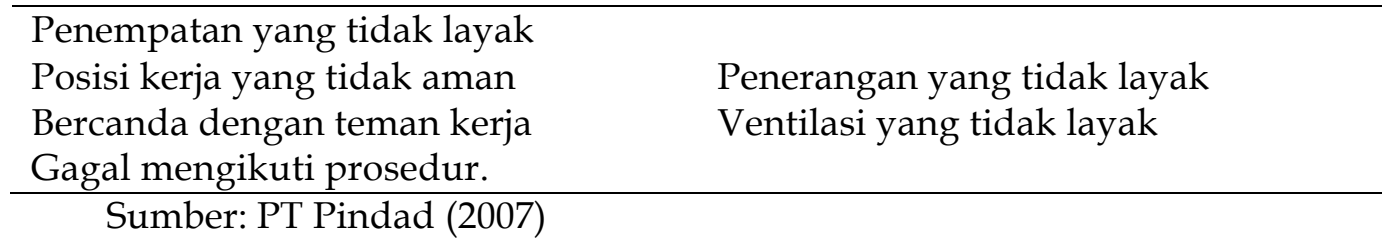

Kerugian atau kecelakaan menyebarkan kuisioner pada bulan dapat berkaitan dengan empat hal Mei 2014 pada karyawan Subdep yaitu manusia, peralatan, material, Perkakas dan melakukan dan lingkungan; misalnya jatuhnya wawancara dengan Kepala Subdep korban luka maupun korban jiwa, Perkakas untuk mendapatkan rusaknya peralatan maupun gambaran yang lebih utuh. Penilaian material yang digunakan untuk tingkat kejadian dan dampak isiko bekerja karena kecelakaan, terkait aktivitas rutin ditulis pencemaran lingkungan, human berdasarkan Identifikasi dan error, dan sebagainya. Paradigma Penilaian Risiko Bahaya di Subdep yang digunakan dalam penelitian ini Perkakas yang telah dimiliki oleh PT digambarkan dalam diagram gambar 2.

Metode Penelitian

3.1 Metodologi

Pindad (Persero) - Divisi Munisi; sedangkan penilaian tingkat kejadian dan dampak risiko terkait perilaku manusia, infrastruktur, dan Penelitian ini menggunakan pendekatan kuantitatif yang dilengkapi dengan peralatan kerja dilakukan melalui penyebaran kuisioner pada karyawan Subdep Perkakas.

pendekatan kualitatif. Penulis 


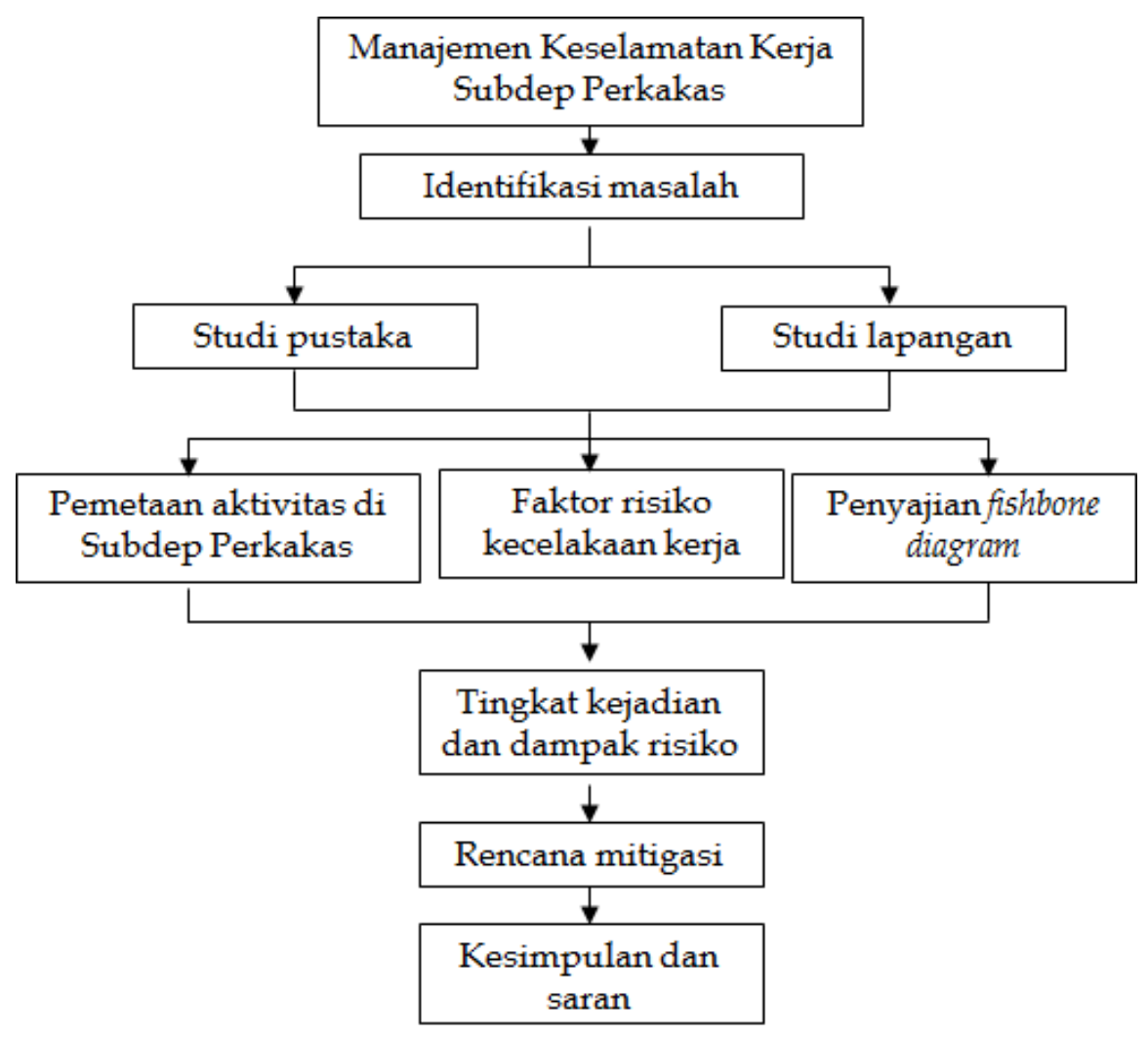

Gambar 2: Rerangka Pikiran

3.2 Teknik sampling

Teknik pengambilan

sampel yang digunakan dalam penelitian ini adalah purposive sampling. Singh (2007) menyatakan bahwa purposive sampling digunakan bila penelitian memiliki target sampel yang jelas dan pemilihan responden secara acak bukan merupakan perhatian utama. Dalam penelitian ini, yang dimaksud dengan target sampel adalah seluruh karyawan yang ada di Subdep Perkakas. Menurut data yang diberikan oleh Subdep K3LH, jumlah populasi dalam penelitian ini adalah 33 orang; sehingga keseluruhan populasi sebagai responden penelitian karena jumlah populasi relatif kecil atau berjumlah kurang dari 30 orang (Sekaran, 2006).

\subsection{Alat ukur}

Kuisioner yang digunakan menggunakan skala likert 1 sampai 5 dan dapat dilihat pada bagian lampiran. Berikut ini merupakan keterangan skala likert yang 
digunakan:1: sangat buruk2: buruk;

3:cukup; 4: baik; 5: sangat baik

Terdapat delapan hal yang

perlu diperhatikan dalam proses identifikasi risiko menurut OHSAS 18001:2007 namun penulis hanya akan menggunakan tiga hal sebagai variabel penelitian ini. Berikut ini merupakan variabel yang digunakan:

1. Variabel risiko, tingkat kejadian, dan dampak risiko terkait aktivitas rutin. Tingkat kejadian risiko merupakan kemungkinan terjadinya suatu risiko dalam suatu aktivitas; sedangkan dampak risiko merupakan akibat yang muncul pada seseorang atau perusahaan bila suatu risiko terjadi. Tingkat kejadian dan dampak risiko akan diukur untuk masing-masing risiko yang ditemukan. Definisi operasional ini juga berlaku untuk tingkat kejadian dan dampak risiko terkait faktor perilaku manusia serta infrastruktur dan peralatan yang disediakan.

2. Variabel risiko, tingkat kejadian, dan dampak risiko terkait perilaku manusia. Variabel risiko perilaku manusia berhubungan dengan risiko yang berkaitan dengan tingkah laku, kebiasaan, dan kemampuan karyawan ketika bekerja. Indikator yang akan digunakan dalam variabel ini adalah:

a. Pemahaman terhadap SOP (Aksorn dan Hadikusumo 2007, Abdelhamid dan Everett 2000, Destrianty, Prassetiyo, dan Ginanjar 2012)

b. Kepatuhan terhadap SOP (Abdelhamid dan Everett 2000)

c. Kebiasaan dalam menggunakan alat pelindung diri (APD) (Kurniawati, Sugiono, dan Yuniarti 2013, Kusuma 2011)

d. Kebiasaan dalam menjaga kerapian tempat kerja (Abdelhamid dan Everett 2000, Kurniawati, Sugiono, dan Yuniarti 2013)

e. Pengawasan keselamatan kerja (safety patrol) (Aksorn dan Hadikusumo 2007)

f. Pengalaman kerja yang dimiliki (Gyekye dan Salminen 2010, Aksorn dan Hadikusumo 2007) 
g. Pelatihan yang pernah diikuti

(Aksorn dan Hadikusumo 2007, Kusuma 2011)

3. Variabel risiko, tingkat kejadian, serta dampak risiko terkait infrastruktur dan peralatan yang disediakan

Variabel ini berkaitan dengan kondisi yang ada di tempat kerja dan peralatan yang mereka gunakan. Indikator yang akan digunakan adalah:

a. Kondisi suhu udara (Yuliawati dan Putri 2010, Pitasari, Wahyuning, dan Desrianty 2014)

b. Kondisi penerangan (Pitasari, Wahyuning, dan Desrianty 2014)

c. Kondisi peralatan kerja (Abdelhamid dan Everett 2000, Aksorn dan Hadikusumo 2007, Pitasari, Wahyuning, dan Desrianty 2014)

\subsection{Cara Analisis}

Hasil kuisioner dianalisa dengan nilai rata-rata (mean) untuk mendapatkan gambaran mengenai kondisi masing-masing indikator, tingkat kejadian, dan dampak risiko terkait perilaku manusia, infrastruktur, dan peralatan kerja. Setelah itu, peneliti menggolongkan risiko berdasarkan matriks tingkat kejadian dan dampak risiko. Misalnya, tingkat kejadian suatu risiko tergolong dalam kategori kondisi abnormal sedangkan dampak risiko tergolong dalam kategori first aid injury. Risiko ini tergolong dalam risiko rendah berdasarkan matriks tersebut (dapat dilihat pada tabel 1). Selanjutnya, peneliti mengadakan wawancara dengan Subdep Perkakas untuk mendeskripsikan kondisi kerja dengan lebih jelas dan merumuskan penanganan risiko yang tepat.

\section{Hasil dan Pembahasan}

Berdasarkan Identifikasi dan Penilaian Risiko Bahaya di Subdep Perkakas yang telah dimiliki oleh PT Pindad (Persero) - Divisi Munisi dan hasil kuisioner, dapat dilihat bahwa Subdep Perkakas memiliki 21 risiko kecelakaan kerja sebagai berikut:

Tabel 4

Daftar Risiko Kecelakaan Kerja di Subdep Perkakas 


\begin{tabular}{|c|c|c|c|c|}
\hline No. & Daftar Risiko & Tingkat Kejadian & Dampak Risiko & $\begin{array}{l}\text { Kategori } \\
\text { Risiko } \\
\end{array}$ \\
\hline 1 & Tersengat listrik & Jarang sekali & Minor & Rendah \\
\hline 2 & Tergores peralatan & Jarang sekali & First aid injury & Rendah \\
\hline 3 & Tersayat peralatan & Jarang sekali & Minor & Rendah \\
\hline 4 & Terkilir & Jarang sekali & First aid injury & Rendah \\
\hline 5 & Terpukul peralatan & Jarang sekali & First aid injury & Rendah \\
\hline 6 & $\begin{array}{l}\text { Terkena debu dan } \\
\text { geram gerinda }\end{array}$ & Sering sekali & First aid injury & Rendah \\
\hline 7 & $\begin{array}{l}\text { Terkena pecahan } \\
\text { batu gerinda }\end{array}$ & Jarang sekali & Major & Sedang \\
\hline 8 & Terlilit geram & Jarang sekali & First aid injury & Rendah \\
\hline 9 & $\begin{array}{l}\text { Terkena semburan } \\
\text { cutting oil }\end{array}$ & Jarang sekali & First aid injury & Rendah \\
\hline No. & Daftar Risiko & Tingkat Kejadian & Dampak Risiko & $\begin{array}{l}\text { Kategori } \\
\text { Risiko }\end{array}$ \\
\hline 10 & $\begin{array}{l}\text { Tertimpa benda } \\
\text { kerja }\end{array}$ & Jarang sekali & First aid injury & Rendah \\
\hline 11 & Kelelahan & Jarang sekali & First aid injury & Rendah \\
\hline 12 & Pemahaman SOP & Kejadian abnormal & First aid injury & Rendah \\
\hline 13 & Kepatuhan SOP & Kejadian abnormal & Minor & Rendah \\
\hline 14 & Kepatuhan APD & Kejadian abnormal & Minor & Rendah \\
\hline 15 & $\begin{array}{l}\text { Kerapian tempat } \\
\text { kerja }\end{array}$ & Kejadian abnormal & First aid injury & Rendah \\
\hline 16 & Safety patrol & Kejadian abnormal & First aid injury & Rendah \\
\hline 17 & Pengalaman kerja & Kejadian abnormal & First aid injury & Rendah \\
\hline 18 & Pelatihan kerja & Kejadian abnormal & Minor & Rendah \\
\hline 19 & Kondisi suhu udara & Kejadian abnormal & First aid injury & Rendah \\
\hline 20 & $\begin{array}{l}\text { Kondisi } \\
\text { penerangan }\end{array}$ & Kejadian abnormal & First aid injury & Rendah \\
\hline 21 & $\begin{array}{l}\text { Kondisi peralatan } \\
\text { kerja }\end{array}$ & Kejadian abnormal & First aid injury & Rendah \\
\hline
\end{tabular}

Berdasarkan skala likert, (didapatkan dari rumus (nilai berikut ini merupakan keterangan dan skor terkait hasil rata-rata tertinggi-nilai terendah)/banyaknya kuisioner mengenai perilaku kelas):Skor $\quad 0,00 \quad-\quad 1,00:$ Sangat manusia, infrastruktur, dan burukSkor 3,01 - 4,00 : BaikSkor 1,01 peralatan kerja di Subdep Perkakas - 2,00: BurukSkor 4,01-5,00:Sangat baik. Skor 2,01-3,00: Cukup

Tabel 5Hasil Kuisioner Kondisi Perilaku Manusia, Infrastruktur, dan Peralatan di Subdep Perkakas

\begin{tabular}{llll}
\hline No. Indikator & Skor & Rata-rata & Standar \\
\hline
\end{tabular}




\begin{tabular}{lllll}
\hline & & Kuisioner & deviasi & \\
\hline 1 & Pemahaman SOP & 3,74 & 0,89 & Baik \\
2 & Kepatuhan SOP & 4,00 & 0,97 & Baik \\
3 & Penggunaan APD & 4,55 & 0,56 & Sangat baik \\
4 & Kerapian tempat kerja & 4,47 & 0,63 & Sangat baik \\
5 & Safety patrol & 3,44 & 1,08 & Baik \\
6 & Pengalaman kerja & 3,33 & 1,30 & Baik \\
7 & Pelatihan kerja & 3,38 & 1,16 & Baik \\
8 & Suhu udara & 2,59 & 1,26 & Cukup \\
9 & Penerangan & 3,63 & 1,00 & Baik \\
10 & Peralatan kerja & 4,16 & 0,77 & Sangat baik \\
\hline
\end{tabular}

Menurut Santoso (2005), data kuisioner yang ada, dapat penghitungan korelasi data nondibuat suatu tabel korelasi parametrik dapat dilakukan dengan uji korelasi Spearman dan uji Spearman antar variabel sebagai berikut:

korelasi Kendall's tau. Berdasarkan

Tabel 6Tabel Korelasi Antar Variabel dalam Kuisioner

\begin{tabular}{lll}
\hline Indikator & Poin Pertanyaan & Nilai Korelasi \\
\hline Pemahaman terhadap & Sosialisasi SOP & 0,819 \\
SOP (Standar & Pemahaman SOP & 0,660 \\
Operasional Prosedur) & Informasi SOP & 0,575 \\
& Kesadaran SOP & 0,682 \\
Kepatuhan SOP & Kesesuaian SOP & 0,687 \\
& Dasar kepatuhan & 0,706 \\
Penggunaan APD & Penggunaan APD & 0,530 \\
& Kebiasaan penggunaan & 0,653 \\
Kerapian tempat kerja & Dasar penggunaan & 0,626 \\
& Kerapian peralatan & 0,437 \\
Safety patrol & Kerapian tempat & 0,413 \\
Pengalaman kerja & Dasar kerapian & 0,841 \\
& Adanya safetypatrol & 0,860 \\
Eelatihan kerja & Efektivitas safety patrol & 0,842 \\
& Adanya pengalaman kerja & 0,942 \\
& Manfaat pengalaman kerja & 0,954 \\
Suhu udara & Adanya pelatihan internal & 0,383 \\
Penerangan & Adanya & 0,684 \\
\hline & eksternal pelatihan & \\
& Manfaat pelatihan & 0,841 \\
& Kondisi suhu & 0,450 \\
& Pengecekan suhu & 0,765 \\
& Efektivitas pengecekan & 0,568 \\
Kondisi penerangan & 0,603 \\
\hline
\end{tabular}




\begin{tabular}{lll}
\hline & Maintenance penerangan & 0,734 \\
& Pengaruh maintenance & 0,705 \\
Kendisi peralatan & 0,773 \\
Keralatan kerja & Maintenance peralatan & 0,635 \\
& Efektivitas maintenance & 0,683 \\
\hline
\end{tabular}

Dari hasil tabel korelasi tersebut, dapat dilihat bahwa semua poin pertanyaan memiliki nilai positif terhadap variabel yang ada sehingga poin pertanyaan memiliki hubungan arah yang sama. Sebagai contoh, semakin tinggi sosialisasi SOP pada karyawan, semakin tinggi pemahaman SOP. Nilai korelasi yang bernilai lebih besar dari 0,5 menunjukkan bahwa poin pertanyaan berkorelasi erat; sedangkan nilai korelasi yang bernilai kurang dari 0,5 menunjukkan bahwa poin pertanyaan berkorelasi kurang kuat (Singgih, 2006). Untuk signifikansi masing-masing poin pertanyaan, pertanyaan kuisioner memiliki hubungan signifikan dengan variabel yang ditentukan karena hasil Sig. (2-tailed) poin pertanyaan lebih kecil dari 0,05. Pada akhirnya, dapat disimpulkan bahwa poin kerapian peralatan, kerapian tempat, adanya pelatihan internal, dan kondisi suhu memiliki korelasi searah kurang kuat yang signifikan dengan masing-masing variabelnya; sedangkan poin lainnya memiliki korelasi searah kuat yang signifikan dengan masing-masing variabelnya.

Berdasarkan wawancara lebih lanjut dengan Subdep Perkakas, hasil kuisioner telah menunjukkan kondisi di Subdep Perkakas dengan tepat. Hal yang perlu ditambahkan adalah kondisi mengenai penggunaan APD dan suhu udara. Para karyawan masih sering tidak menggunakan kacamata pelindung ketika bekerja. Hal ini terjadi karena kacamata tersebut cepat buram setelah digunakan beberapa kali dan mereka tidak terbiasa menggunakan kacamata. Kacamata tersebut cepat buram karena terbuat dari bahan plastik dan karyawan terbiasa mengelap kacamata dengan kain seadanya. Untuk kondisi suhu udara, sebenarnya sudah ada kipas angin yang dipasang pada beberapa titik namun hal ini masih belum dapat menciptakan kondisi kerja dengan suhu yang nyaman. 
Berdasarkan hasil yang ada dapat disimpulkan bahwa Subdep Perkakas menghadapi 20 risiko kategori rendah dan 1 risiko kategori sedang. Risiko dengan kategori rendah diatasi dengan kontrol administratif dan penggunaan APD; sedangkan risiko dalam kategori medium ditangani dengan engineering control dan penggunaan APD. Berikut ini langkah penanganan risiko yang berhasil dirumuskan dalam proses wawancara:

Tabel 7Langkah Penanganan Risiko Terkait Aktivitas Rutin, Perilaku Manusia, Infrastruktur, dan Peralatan Kerja di Subdep Perkakas

\begin{tabular}{|c|c|c|}
\hline No. & Daftar Risiko & Langkah Penanganan \\
\hline 1 & Tersengat listrik & $\begin{array}{l}\text { Pengecekan kondisi panel listrik secara } \\
\text { berkala melalui safety patrol, tanda peringatan, } \\
\text { dan penyediaan alat pemadam api ringan }\end{array}$ \\
\hline No. & Daftar Risiko & Langkah Penanganan \\
\hline 2 & Tergores peralatan & Penggunaan sarung tangan \\
\hline 3 & Tersayat peralatan & $\begin{array}{l}\text { Penggunaan sarung tangan dan pemasangan } \\
\text { pengaman mesin }\end{array}$ \\
\hline 4 & Terkilir & Penataan layout mesin \\
\hline 5 & Terpukul peralatan & Pemasangan pengaman mesin \\
\hline 6 & $\begin{array}{l}\text { Terkena debu dan } \\
\text { geram gerinda }\end{array}$ & $\begin{array}{l}\text { Penggunaan masker kain, kacamata } \\
\text { pelindung, dan sarung tangan }\end{array}$ \\
\hline 7 & $\begin{array}{l}\text { Terkena pecahan batu } \\
\text { gerinda }\end{array}$ & Penggunaan kacamata pelindung \\
\hline 8 & Terlilit geram & Pemasangan alat pengaman mesin \\
\hline 9 & $\begin{array}{l}\text { Terkena semburan } \\
\text { cutting oil dalam proses } \\
\text { bor }\end{array}$ & Pemasangan alat pengaman mesin \\
\hline 10 & Tertimpa benda kerja & Penggunaan safety shoes \\
\hline 11 & Kelelahan & $\begin{array}{l}\text { Penataan layout mesin dan menjaga sirkulasi } \\
\text { udara }\end{array}$ \\
\hline 12 & Pemahaman SOP & $\begin{array}{l}\text { Pemberian pelatihan dan pengarahan sebelum } \\
\text { karyawan bekerja }\end{array}$ \\
\hline 13 & Kepatuhan SOP & $\begin{array}{l}\text { Pemantauan hasil kerja dan safety briefing } \\
\text { Safety briefing, penyediaan APD yang lebih }\end{array}$ \\
\hline 14 & Kepatuhan APD & $\begin{array}{l}\text { nyaman, pengadaan kacamata pelindung } \\
\text { dengan bahan kaca, dan pengarahan } \\
\text { mengenai perawatan APD }\end{array}$ \\
\hline 15 & Kerapian tempat kerja & $\begin{array}{l}\text { Safety briefing dan penegakan peraturan } \\
\text { melalui catatan rekapitulasi pelanggaran }\end{array}$ \\
\hline 16 & Safety patrol & $\begin{array}{l}\text { Pembuatan instruksi kerja safety patrol, } \\
\text { pelaksanaan safety patrol secara rutin, dan } \\
\text { perbaikan temuan }\end{array}$ \\
\hline
\end{tabular}




\begin{tabular}{lll}
\hline No. & Daftar Risiko & Langkah Penanganan \\
\hline 17 & Pengalaman kerja & $\begin{array}{l}\text { Seleksi terhadap calon karyawan } \\
\text { Pemberian pelatihan secara berkala }\end{array}$ \\
18 & Pelatihan kerja & $\begin{array}{l}\text { Pemasangan kipas angin dan realisasi } \\
\text { pemasangan alat sirkulasi udara pada atap } \\
\text { Subdep Perkakas }\end{array}$ \\
20 & Kondisi suhu udara & $\begin{array}{l}\text { Pengecekan secara berkala dari UPTK3 dan } \\
\text { penggantian penerangan bila sudah tidak } \\
\text { memadai } \\
\text { Maintenance secara teratur dan penggantian } \\
\text { peralatan jika sudah tidak layak dipakai }\end{array}$ \\
\hline
\end{tabular}

Secara keseluruhan, risiko

kecelakaan kerja di Subdep Perkakas dapat digambarkan dalam fishbone diagram sebagai berikut ini:

Gambar 3: $\quad$ Fishbone Diagram Faktor Risiko yang Dapat Mengakibatkan Kecelakaan Kerja di Subdep Perkakas

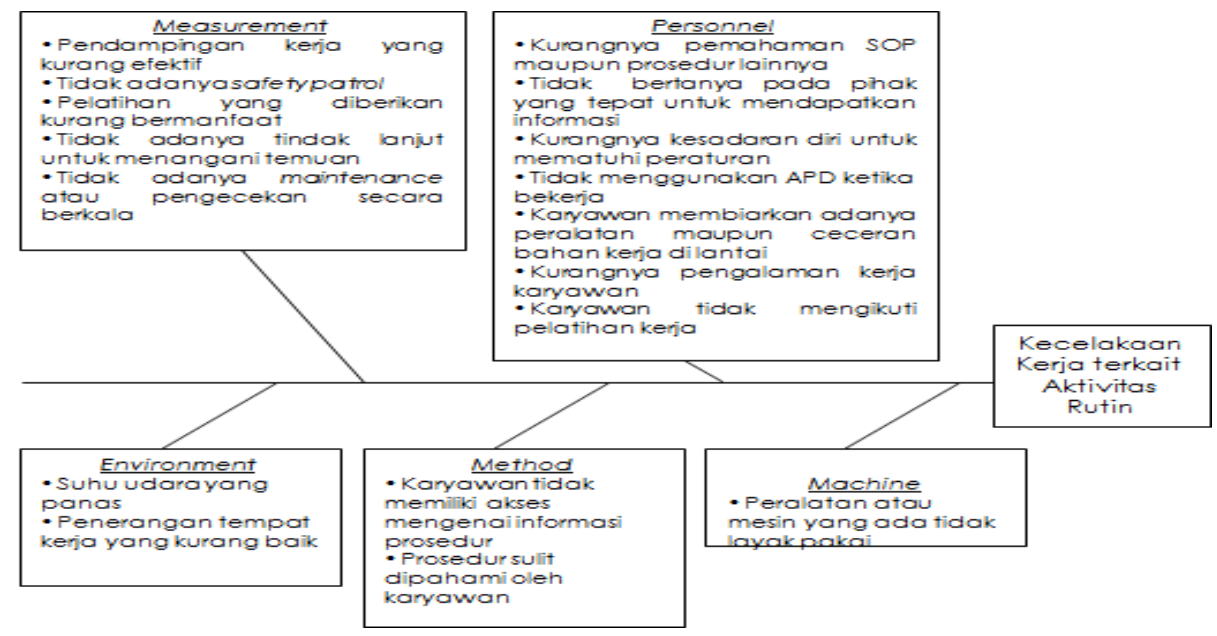

Subdep Perkakas PT Pindad

(Persero) - Divisi Munisi telah memiliki manajemen keselamatan kerja yang baik karena tidak pernah mengalami kecelakaan kerja selama beberapa tahun terakhir. Subdep Perkakas memiliki 20 risiko kecelakaan kategori rendah dan 1 risiko kecelakaan kategori sedang yang terbagi menjadi risiko aktivitas rutin, perilaku manusia, dan infrastruktur serta peralatan yang disediakan. Seluruh risiko yang ada dapat ditangani dengan kontrol administratif berupa penetapan SOP dan penggunaaan APD. Kondisi kepatuhan penggunaan APD di Subdep Perkakas dapat ditingkatkan dengan menyediakan kacamata pelindung dengan bahan kaca dan pengarahan mengenai perawatan 
APD. Kondisi suhu udara dapat ditingkatkan lagi melalui pemasangan alat sirkulasi udara di atap Subdep Perkakas.

Secara keseluruhan,
temuan dalam penelitian ini
memberikan kontribusi dalam teori
penyebab kecelakaan kerja.
Penelitian ini mendukung model
penyebab dan akibat kecelakaan
kerja yang dikemukakan oleh Bird
dan Germain dalam panduan SMK3
PT Pindad (Persero). Model tersebut
menunjukkan bahwa kecelakaan
kerja dapat dicegah bila perusahaan
memiliki kontrol manajemen yang
baik. Subdep Perkakas PT Pindad
(Persero) - Divisi Munisi telah memiliki kontrol manajemen yang baik untuk setiap risiko yang dihadapinya dan hal ini terbukti dengan tidak adanya kecelakaan kerja selama beberapa tahun. Di Subdep Perkakas masih ada perbuatan dan kondisi tidak aman seperti tidak digunakannya kacamata pelindung dan panasnya suhu udara; namun hal ini tidak membuat Subdep Perkakas mengalami kecelakaan kerja yang fatal.
Kelemahan penelitian ini adalah standar deviasi kuisioner pertanyaan yang bervariasi antara 0,77 hingga 1,30. Misalnya, rata-rata poin pemahaman SOP adalah 3,74 sedangkan standar deviasinya adalah 0,89. Hal ini berarti nilai kuisionernya berkisar antara 2,85 hingga 4,63 yang didapat dari ratarata kuisioner \pm standar deviasinya $(3,74 \pm 0,89)$. Hal ini menunjukkan bahwa pemahaman SOP sangat bervariasi antara cukup, baik, dan sangat baik. Suatu kuisioner dianggap baik bila standar deviasinya mengelompok di sekitar rata-rata hitung; sehingga nilai poin pemahaman SOP seharusnya berada pada rentang 3,00 - 4,00 karena poin pemahaman SOP berada pada kategori baik. Untuk menghindari tingginya standar deviasi ini, peneliti selanjutnya dapat menggunakan skala likert dengan tiga kategori saja yaitu kurang, cukup, dan baik. Dengan hal ini, diharapkan bahwa standar deviasi dapat mengecil karena rentang jawaban yang lebih kecil. 


\section{Daftar Referensi}

Abdelhamid, T., Everett, J. (2000).

Identifying Root Causes of

Construction

Accidents.

Journal of Construction

Engineering and Management, 52-60.

Aksorn, T., \& Hadikusumo, B. (2007). Gap Analysis Approach for Construction Safety Program Improvement. Journal of Construction in Developing Countries, 12 (1), 77-97.

Destrianty, A., Prassetiyo, H., Ginanjar, G. (2012). Rancangan Sistem Keselamatan Kerja Berdasarkan Metode SWIFT (The Structured What-If Analysis) (Studi Kasus di Stasiun Kerja Belt Grinding Unit PRASKA PT Pindad

Persero Bandung). Prosiding Seminar Nasional Teknoin 2012.

Djaali dan Muljono. (2008). Pengukuran dalam Bidang Pendidikan. Jakarta, Indonesia: PT. Grasindo.

Dunmire, T. (2002). Measuring Up to the World. ProQuest Nursing $\mathcal{E} \quad$ Allied Health SourceOccupational Health and Safety, 71, 233-236.
Gyekye, S., Salminen, S. (2010). Organizational Safety Climate and Work Experience. International Journal of Occupational Safety and Ergonomics, 16 (4), 431-443.

Kurniawati, E., Sugiono, Yuniarti, R. (2012). Analisis Potensi Kecelakaan Kerja Pada Departemen Produksi Springbed dengan Metode Hazard Identification and Risk Assessment (HIRA) (Studi Kasus: PT. Malindo Intitama Raya, Malang, Jawa Timur).

Kusuma, I. (2011). Pelaksanaan Program Keselamatan dan Kesehatan Kerja Karyawan di PT Bitratex Industries Semarang.

OHSAS. (2007). OHSAS 18001:2007 Occupational Health and Safety Assessment Series.

Pitasari, G., Wahyuning, C., Desrianty, A. (2014). Analisis Kecelakaan Kerja untuk Meminimisasi Potensi Bahaya Menggunakan Metode Hazard and Operability dan Fault Tree Analysis (Studi Kasus di PT X). Jurnal Online Institut Teknologi Nasional, 2 (2), 167-179. 
PT Pindad (Persero). (2007).

Panduan SMK3 PT Pindad

(Persero).

Sekaran, U. (2006). Metodologi

Penelitian untuk Bisnis Edisi 4.

Jakarta, Indonesia: Salemba

Empat.

Singgih, S. (2006). SSBBTI: SPSS

Statistik Non-Parametrik + CD.

Jakarta, Indonesia: PT Elex

Media Komputindo.
Singh, K. (2007). Quantitative Social

Research Methods. New Delhi, India: Sage Publications India Pvt Ltd.

Yuliawati, S., Putri, S. (n.d.).

Analisis Risiko Keselamatan dan Kesehatan Kerja pada Proses

Produksi PT. Abadi Adimulia.

\section{Lampiran}

Pemahaman terhadap SOP (Standar Operasional Prosedur)

Apakah Anda setuju untuk mengikuti sosialisasi

1 mengenai SOP terkait proses kerja yang Anda $\begin{array}{llllll}1 & 2 & 3 & 4 & 5\end{array}$ lakukan?

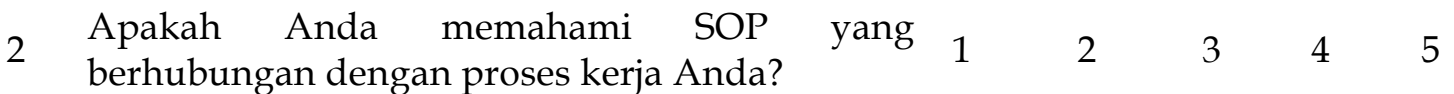

3 Bila Anda tidak memahami SOP yang ada, $1 \quad 2 \quad 3 \quad 4 \quad 5$ apakah Anda bertanya pada atasan Anda?

Kepatuhan terhadap SOP

1 Apakah Anda menyadari pentingnya SOP dalam melakukan proses kerja?

2 Apakah Anda selalu bekerja sesuai dengan SOP yang berlaku?

Apakah Anda menjalankan SOP dengan
kesadaran sendiri?

Kebiasaan dalam menggunakan APD

Apakah Anda menggunakan semua APD yang

1 telah ditentukan di proses kerja Anda ketika $11 \quad 2 \quad \begin{array}{lllll}3 & 4 & 5\end{array}$ bekerja?

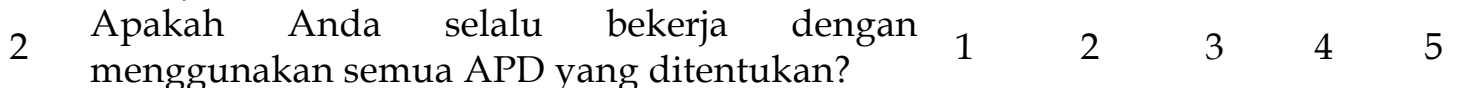

3 Apakah Anda menggunakan APD berdasarkan $1 \begin{array}{llllll} & 2 & 3 & 4 & 5\end{array}$

Kebiasaan dalam merapikan tempat kerja

Apakah Anda mengembalikan benda kerja

1 maupun peralatan lainnya ke tempat semula $\begin{array}{llllll}1 & 2 & 3 & 4 & 5\end{array}$ sesudah bekerja?

2 Apakah Anda menjaga kebersihan dan tidak $\begin{array}{lllllll}1 & 2 & 3 & 4 & 5\end{array}$ 
membiarkan ceceran bahan kerja di lantai?

Apakah Anda merapikan tempat
berdasarkan kesadaran sendiri?

Pengawasan keselamatan kerja (safety patrol)

1 Apakah terdapat safety patrol di proses kerja Anda?

Apakah penerapan safety patrol sudah tepat untuk memastikan proses kerja berjalan sesuai

2 dengan ketentuan; misalnya memastikan penggunaan APD dan SOP dijalankan dengan baik setiap saat?

Pengalaman kerja yang dimiliki

Apakah Anda memiliki pengalaman kerja lain

1 yang sejenis dengan proses kerja yang Anda lakukan saat ini?

Apakah pengalaman kerja tersebut bermanfaat

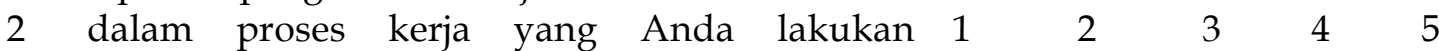
sekarang?

Pelatihan yang pernah diikuti

1 Apakah Anda pernah mengikuti pelatihan kerja yang diadakan oleh PT Pindad (Persero)?

2 Apakah Anda pernah mengikuti pelatihan kerja yang diadakan oleh pihak lain?

3 Apakah pelatihan tersebut membuat kemampuan kerja Anda meningkat?

Kondisi suhu udara

1 Bagaimana kondisi suhu udara ketika Anda bekerja?

Apakah terdapat pengecekan secara berkala

2 mengenai kondisi suhu udara di proses kerja Anda?

Apakah pengecekan tersebut efektif untuk

3 menyediakan tempat kerja dengan suhu udara yang nyaman?

Kondisi penerangan

1 Apakah kondisi penerangan di tempat kerja Anda baik?

Apakah terdapat maintenance atau pengecekan

2 secara berkala atas kondisi penerangan di tempat kerja Anda?

Apakah maintenance atau pengecekan tersebut

3 efektif dalam menyediakan tempat kerja dengan penerangan yang baik?

Kondisi peralatan kerja di subdep perkakas

$1 \quad$ Apakah kondisi peralatan kerja Anda baik? $\quad \begin{array}{llllll}1 & 2 & 3 & 4 & 5\end{array}$

$\begin{array}{llllllll}\text { Apakah terdapat maintenance atau pengecekan } & 1 & 2 & 3 & 4 & 5\end{array}$

3 Apakah maintenance atau pengecekan tersebut $\begin{array}{llllll}1 & 2 & 3 & 4 & 5\end{array}$ 
efektif dalam menyediakan peralatan kerja yang baik setiap saat?

Seberapa besar kemungkinan munculnya

1 risiko kecelakaan kerja karena kurangnya $1 \begin{array}{lllllll}1 & 2 & 3 & 4 & 5\end{array}$ kepatuhan terhadap SOP?

Apa dampak yang terjadi karena kurangnya

kepatuhan terhadap SOP?

Seberapa besar kemungkinan munculnya

3 risiko kecelakaan kerja karena kurangnya kepatuhan terhadap SOP?

$4 \quad$ Apa dampak yang terjadi karena kurangnya

kepatuhan terhadap SOP?

No Pertanyaan

Seberapa besar kemungkinan terjadinya

5 kecelakaan kerja karena ketidakpatuhan dalam penggunaan APD?

Apa dampak yang terjadi karena tidak patuh dalam menggunakan APD?

Seberapa besar kemungkinan terjadinya

kecelakaan kerja karena tempat kerja yang tidak rapi?

Apa dampak yang terjadi karena tempat kerja yang tidak rapi?

Seberapa besar kemungkinan munculnya risiko kecelakaan kerja karena safety patrol tidak sedang dilakukan?

Apa dampak yang terjadi karena safety patrol tidak sedang dilakukan?

Seberapa besar kemungkinan terjadinya

11 kecelakaan kerja karena sedikitny pengalaman kerja yang dimiliki?

Apa dampak yang mungkin terjadi karena sedikitnya pengalaman kerja yang dimiliki?

Seberapa besar kemungkinan terjadinya

13 kecelakaan kerja karena kurangnya pelatihan yang pernah diikuti?

Apa dampak yang mungkin terjadi karena kurangnya pelatihan yang pernah diikuti?

Seberapa besar kemungkinan terjadinya kecelakaan kerja karena panasnya suhu udara?

Apa dampak yang terjadi karena panasnya suhu udara?

Seberapa besar kemungkinan terjadinya

17 kecelakaan kerja karena kondisi penerangan yang kurang baik?

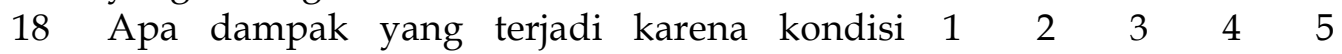


penerangan yang kurang baik?

Seberapa besar kemungkinan terjadinya

19 kecelakaan karena kondisi peralatan kerja $\begin{array}{llllll}1 & 2 & 3 & 4 & 5\end{array}$ yang kurang baik? $\begin{array}{llllllll}20 & \begin{array}{l}\text { Apa dampak yang terjadi karena } \\ \text { peralatan kerja yang kurang baik? }\end{array} & & 1 & 2 & 3 & 4 & 5\end{array}$ 